\title{
Rheumatoid pericardial effusion with heart block treated by pericardiectomy and implantation of permanent pacemaker
}

\author{
ALAN GELSON, J. M. SANDERSON, AND PETER CARSON \\ From the North Staffordshire Hospital Group, Stoke-on-Trent
}

A patient with long-standing seropositive erosive rheumatoid arthritis developed a pericardial effusion with chronic cardiac tamponade. He had evidence of conducting system disease and developed heart block. He was successfully treated by pericardiectomy and implantation of a demand pacemaker.

Pericardial effusion is a well-recognised but clinically unusual complication of rheumatoid arthritis and there have been several descriptions of both acute and chronic cardiac tamponade (Granirer, 1946; Bevans et al., 1954; Stern and Sobel, 1961 ; Szatkowski and Inoue, 1963; Kennedy, Partridge, and Matthews, 1966; Latham, 1966; Sutton, 1967; Romanoff, Rozin, and Zlotnick, 1970; Franco, Levine, and Hall, 1972; Thadani, Iveson, and Wright, 1975). Constrictive pericarditis has also been described as a complication of rheumatoid arthritis (Tubbs, Slade, and TurnerWarwick, 1964; Harrold, 1968; Pitt et al., 1969).

Heart block with rheumatoid arthritis has also been previously described (Handforth and Woodbury, 1959; Gowans, 1960; Hoffman and Leight, 1965; Cathcart and Spodick, 1962; Lebowitz, 1963). However, we have been able to find only two previous case reports of effusion with tamponade complicated by heart block (Handforth and Woodbury, 1959; Metzger, 1970) and in neither was there a successful surgical outcome.

\section{Case report}

A detective sergeant, born in 1920, presented in 1963 with recurrent knee effusion. In 1969 he developed pain and stiffness in the shoulders, elbows, and hands. His rheumatoid factor was weakly positive but no LE cells could be detected. The chest radiograph showed a normal-sized heart (cardiothoracic ratio 0.46 ) and clear lung fields. His symptoms settled with salicylates, and later phenylbutazone and indomethacin. However, in March 1972 he relapsed with evidence of severe generalised rheumatoid disease. He spent three months in hospital. During this time he ran a slight fever and developed pericarditis with pain and a persistent rub. The cardiothoracic ratio increased to 0.52 . He was started on corticosteroids and after discharge home he attended the clinic. His symptoms remained relatively quiescent taking $20 \mathrm{mg}$ prednisolone a day. During 1972 he began to complain of increasing shortness of breath on exertion, and his chest radiograph showed evidence of pulmonary venous hypertension.

During 1973 his rheumatoid arthritis remained reasonably quiescent but he continued to be moderately short of breath on exertion. His jugular venous pressure was at the upper limit of normal, with a slight inspiratory rise. There was no significant pulsus paradoxus. A pericardial rub was still present. His electrocardiogram (Fig. 1) showed sinus rhythm with first degree heart block (PR interval $0.24 \mathrm{~s}$ ). The $\mathrm{QRS}$ complexes had left bundle-branch block, with left axis deviation (mean frontal QRS axis $-45^{\circ}$ ).

Throughout 1974 he became increasingly breathless and his jugular venous pressure was $5 \mathrm{~cm}$ above the sternal angle with a more pronounced inspiratory rise. He had bilateral basal crepitations. His blood pressure was $140 / 90 \mathrm{mmHg}(18 \cdot 6 / 12 \cdot 0 \mathrm{kPa})$. His electrocardiogram now showed $2: 1 \mathrm{AV}$ block with a ventricular rate of $38 / \mathrm{min}$ (Fig. 2). The conducted beats had right bundle-branch block, with persisting left axis deviation at $-45^{\circ}$. The PR interval was longer $(0.38 \mathrm{~s})$.

By January 1975 he was severely restricted by breathlessness and his jugular venous pressure was raised to the ear lobes. There was a $15 \mathrm{mmHg}$ $(2.0 \mathrm{kPa})$ degree of pulsus paradoxus with persisting basal crepitations. His chest $x$-ray film showed a 


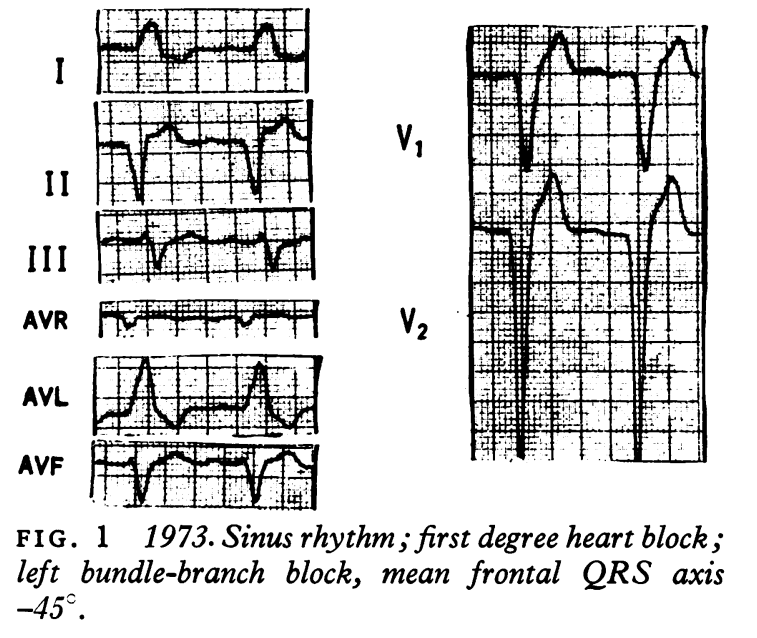

further increase in cardiothoracic ratio to 0.55 , with continuing evidence of pulmonary venous hypertension. His electrocardiogram still showed 2:1 AV block. He had continued on $20 \mathrm{mg}$ prednisolone a day.

Right heart catheterisation was performed and, as expected, showed raised right-sided and wedge pressures, with very similar diastolic pressures in the right heart chambers and the wedge pressure. $R A$ a $=21, x=19, v=20, y=17$, mean $=20$.

RV 33/18. PA $30 / 19$, PC $a=20, x=20, v=28$, $y=18$, mean $=20$.

Since these raised diastolic pressures could possibly be the result in part of the slow heart rate rather than of pericardial restriction the right ventricle was paced at 80 beats/min while the pressure measurements were repeated; there was no significant change in the right heart or wedge pressures at this faster rate and the diastolic dip and plateau appearance remained in the right ventricular trace. Several attempts were made to advance the catheter tip to the right border of the heart at mid right atrial level. Failure to achieve this suggested the presence of at least moderate pericardial thickening or effusion.

His bundle electrograms revealed a normal $\mathrm{AH}$ interval of $75 \mathrm{~m}$ and, as expected, a prolonged $\mathrm{HQ}$ interval of $300 \mathrm{~m}$ (normal $41 \pm 4 \mathrm{~m}$ ).

After cardiac catheterisation with $\mathrm{His}$ electrograms the patient transiently developed complete heart block but without any slowing of ventricular rate, so that we did not consider it essential to insert a temporary pacemaker. Nevertheless, two Adams-Stokes attacks occurred within the next few hours. He remained in complete heart block and
I

II
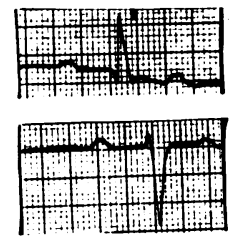

AVR

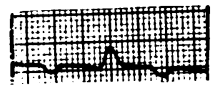

II

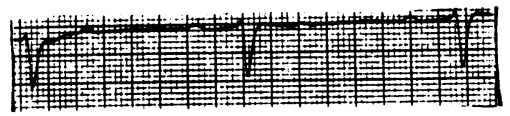

FIG. 2 1974. 2:1 AV klock, right tundle-branch block, $Q R S$ axis $-45^{\circ}$. was referred for urgent surgery. A median sternotomy revealed a thickened pericardium which contained 200 to $300 \mathrm{ml}$ yellow, slightly turbid fluid together with about a tablespoonful of caseous material. A thin peel of tissue was present over the whole heart and was adherent to the parietal pericardium over the apical and lateral aspects of the left ventricle. The anterior, lateral, and apical parts of the left ventricle together with most of the right ventricle were decorticated. A Medtronic model 6917 sutureless (corkscrew) electrode was inserted into the left ventricle and connected to an abdominally sited pacemaker generator. His postoperative course was uneventful and he noticed an increase in well-being, with less dyspnoea. Because of the caseous material found in the pericardium he was started on antituberculous drugs until further investigations into the nature of the pericardial disease had become available. Six months after operation he was back at full-time work taking $12 \mathrm{mg}$ prednisolone daily.

The pericardial fluid contained less than 1.11 $\mathrm{mmol} / \mathrm{l}$ of sugar. The Latex fixation test was positive but the antinuclear factor was negative. No acid-fast bacilli could be seen on direct smear and none grew on subsequent cultures. Histology of the pericardium showed capillary-rich fibrous tissue containing patchy chronic inflammatory exudate consisting of plasma cells and lymphocytes arranged in lymphorrhages. Dr. Ariela Pomerance, of Northwick Park Hospital, thought that these changes, which included lymphoid follicles with germinal centres, were suggestive of rheumatoid disease and that the 'caseous' material had probably originated from the centre of an epicardial rheumatoid granuloma. 


\section{Discussion}

The incidence of pericardial effusion in patients with rheumatoid arthritis is not known with certainty. A clinical study showed a probable incidence based largely on chest $x$-ray evidence of 6 out of 100 cases (Kirk and Cosh, 1969). A recent echocardiographic study suggested a possible incidence of 50 per cent (Bacon and Gibson, 1972). In most cases the effusion is transient, disappearing either spontaneously or with corticosteroid treatment (Bevans et al., 1954; Stern and Sobel, 1961 ; Latham, 1966). Once cardiac tamponade develops pericardiectomy becomes necessary (Kennedy et al., 1966; Thadani et al., 1975).

Heart block is much less common than effusion, and in cases coming to necropsy the cause has been rheumatoid involvement of the conducting system (Handforth and Woodbury, 1959; Gowans, 1960; Hoffman and Leight, 1965). However, one necropsy study (Lebowitz, 1963) of two patients with rheumatoid arthritis who had developed complete heart block showed evidence of healed arteritis and fibrosis of the conducting system, with no mention of granulomata.

Our patient had sero-positive erosive nodular rheumatoid arthritis which had been mild and limited for three years. He developed symptoms and signs of pericarditis at the time that his rheumatoid disease became floridly active. He appeared similar in these respects to previously described patients with rheumatoid pericardial effusion. Rheumatoid effusion has a male predominance. Heart block has been described too infrequently to make any broad generalisations, though cases have been confined to patients with generalised erosive nodular sero-positive rheumatoid arthritis.

Without necropsy proof, fortunately not available in our case, we could not be certain that the conduction disturbances were the result of rheumatoid disease. Nevertheless, we believe that this was the most likely cause, and the absence of angina, the flagrant rheumatoid arthritis, and the changing pattern of ventricular conduction made us decide that coronary arteriography was not necessary or justified.

To the best of our knowledge the combination of these two cardiac complications of rheumatoid arthritis with a successful outcome from operation is extremely rare.

We thank Dr. T. E. Hothersall for referring this case, Dr. Keith Prowse for helping with management, and Dr. Ariela Pomerance for her opinions about histology.

\section{References}

Bacon, P. A., and Gibson, D. G. (1972). Cardiac involvement in rheumatoid arthritis-an echocardiographic study. Annnals of the Rheumatic Diseases, 31, 426.

Bevans, M., Nadell, J., Demartini, F., and Ragan, C. (1954). American fournal of Medicine, 16, 197.

Cathcart, E. S., and Spodick, D. H. (1962). Rheumatoid heart disease. New England fournal of Medicine, 266, 959.

Franco, A. E., Levine, H. D., and Hall, A. P. (1972). Rheumatoid pericarditis. Report of 17 cases diagnosed clinically. Annals of Internal Medicine, 77, 837.

Gowans, J. D. C. (1960). Complete heart block with StokesAdams syndrome due to rheumatoid heart disease. New England fournal of Medicine, 262, 1012.

Granirer, L. W. (1946). Pericardial effusion in rheumatoid arthritis. Medical Clinics of North America, 30, 562.

Handforth, C. P., and Woodbury, J. F. L. (1959). Cardiovascular manifestations of rheumatoid arthritis. Canadian Medical Association fournal, 80, 86.

Harrold, B. P. (1968). Non-tuberculous constrictive pericarditis. British Medical fournal, 1, 290.

Hoffman, F. G., and Leight, L. (1965). Complete atrioventricular block associated with rheumatoid disease. American fournal of Cardiology, 16, 585.

Kennedy, W. P. U., Partridge, R. E. H., and Matthews, M. B. (1966). Rheumatoid pericarditis with cardiac failure treated by pericardiectomy. British Heart fournal, 28, 602.

Kirk, J., and Cosh, J. (1969). The pericarditis of rheumatoid arthritis. Quarterly fournal of Medicine, 38, 397.

Latham, B. A. (1966). Pericarditis associated with rheumatoid arthrit1s. Annals of the Rheumatic Diseases, 25, 235.

Lebowitz, W. B. (1963). The heart in rheumatoid arthritis (rheumatoid disease). A clinical and pathological study of sixty-two cases. Annals of Internal Medicine, 58, 102.

Metzger, A. L. (1970). Discussion on paper by Romanoff et al. Arthritis and Rheumatism, 13, 430.

Pitt, A., Cutforth, R. H., Bender, H. W., Humphries, J. O., Stirling, G. R., Criley, J. M., and Ross, R. S. (1969). Intrapericardial cyst formation in constrictive pericarditis simulating tricuspid stenosis. Circulation, 40, 665.

Romanoff, H., Rozin, R., and Zlotnick, A. (1970). Cardiac tamponade in rheumatoid arthritis. $A$ case report and review of the literature. Arthritis and Rheumatism, 13, 426.

Stern, J. B., and Sobel, H. J. (1961). Hemorrhagic rheumatoid pericarditis. American fournal of Cardiology, 8, 670.

Sutton, R. A. L. (1967). Rheumatoid pericarditis. Proceedings of the Royal Society of Medicine, 60, 339.

Szatkowski, J., and Inoue, T. (1963). Cholesterol pericarditis. An unusual case of probable tubercular origin in a patient with rheumatoid arthritis. American fournal of Cardiology, 12, 730 .

Thadani, U., Iveson, J. M. I., and Wright, V. (1975). Cardiac tamponade, constrictive pericarditis and pericardial resection in rheumatoid arthritis. Medicine, 54, 261.

Tubbs, O. S., Slade, P. R. H., and Turner-Warwick, $M$. (1964). Constrictive pericarditis in association with rheumatoid arthritis. Thorax, 19, 555.

Requests for reprints to Dr. Peter Carson, Cardiology Department, City General Hospital, Newcastle Road, Stoke on Trent ST4 6QG. 